\title{
Reflexóes sobre uma trajetória na Terapia Ocupacional
}

\author{
Selma Lancmam \\ Professora Titular de Terapia Ocupacional, Faculdade de Medicina da Universidade de São Paulo - FMUSP, \\ São Paulo, SP, Brasil
}

\begin{abstract}
Resumo: Esse texto é parte do memorial apresentado como requisito para o concurso de professor titular em Terapia Ocupacional na Faculdade de Medicina da Universidade de São Paulo. As reflexões apresentadas procuram traçar minha trajetória contextualizada nos diversos períodos e instituições por onde passei, apresentando meus percursos e como eles se misturaram com o próprio desenvolvimento acadêmico da Terapia Ocupacional. Procuro discorrer ainda sobre o processo de solidificação de minha formação como pesquisadora e os produtos daí advindos. Tais percursos em pesquisa se construíram e culminaram na linha de pesquisa Saúde Mental e Trabalho e suas interfaces com a Terapia Ocupacional. Por todo o texto, reflito sobre o desenvolvimento acadêmico e científico da área de Terapia Ocupacional sendo que, por fim, aponto discussões acerca da necessária consolidação da área na pesquisa, na pós-graduação e, consequentemente, na divulgação do seu conhecimento por publicações indexadas e de relevância para a área. Acredito que o texto seja simultaneamente um relato pessoal e certo retrato do próprio desenvolvimento da profissão no Brasil, nos últimos trinta anos.
\end{abstract}

Palavras-chave: Terapia Ocupacional, Pesquisa, Saúde Mental, Trabalho.

\section{Reflections on a trajectory in Occupational Therapy}

\begin{abstract}
This text is part of the memorial presented as a requirement of the contest for full professor position in Occupational Therapy at the School of Medicine from the University of Sao Paulo. The reflections presented aim to trace the trajectory contextualized in different periods and institutions where the writer has worked, and how they have blended with the academic development of Occupational Therapy itself. The text also seeks to discuss the solidification process of the writer's training as a researcher and the results arisen thereof. These courses were built on research and culminated in the Mental Health and Work search line and its interfaces with Occupational Therapy. Across the text, the academic and scientific development in the field of occupational therapy is reflected and, finally, discussions are pointed out on the necessary consolidation of the area in research and graduate studies and, therefore, in the dissemination of knowledge by publications indexed and relevant to the field. The text is both a personal account and a true representation of the profession development in Brazil in the past thirty years.
\end{abstract}

Keywords: Occupational Therapy, Research, Mental Health, Work.

\section{Apresentação}

Reler este texto para publicá-lo é recomeçar um intenso processo de reflexão realizado quando escrevi o memorial que integrava os requisitos para o exame de professora titular em Terapia Ocupacional na
Faculdade de Medicina da Universidade de São Paulo no início de 2009. É tentar, depois de muitos anos, dar um significado para fatos e vivências que, embora tenham ocorrido de forma quase casual, ao longo 
do tempo, estavam articuladas e consteladas de uma forma que somente anos depois podemos entender os elos e sentidos. Partilhar essas reflexôes com amigos, colegas, parceiros, coparticipantes, ex-alunos e novos profissionais é expor mais do que minha trajetória pessoal - é partilhar o desenvolvimento de um campo, de uma profissão. Espero poder contribuir na constelação de outras histórias que, de alguma forma, se somaram e se somarão à minha na construção da Terapia Ocupacional.

\section{Ser terapeuta ocupacional - começando}

Quando escolhi cursar a graduação em Terapia Ocupacional na Faculdade de Medicina da Universidade de São Paulo (FMUSP), em 1976, enfrentei certa estranheza por parte dos amigos e parentes, que achavam a escolha um tanto "exótica". Afinal, perguntavam-se todos, que profissão é essa da qual ninguém nunca teve notícia? Eu mesma tinha dificuldade em explicar a decisão e, mesmo empolgada pela possibilidade de trabalhar com reabilitação de pessoas portadoras de deficiências, com grupos de excluídos e usando o fazer como instrumento terapêutico, não entendia bem como esses aspectos se articulavam, ou como isso se constituía numa profissão e num campo de atuação.

Aventurar-me em uma profissão desconhecida, contudo, não me intimidava, ao contrário, me desafiava, pois, desde aquela época, já intuía que meu crescimento pessoal e profissional ocorreriam concomitantes ao desenvolvimento da profissão no país.

Durante o curso de graduação, minhas dúvidas não eram respondidas, poucos professores terapeutas ocupacionais possuíam vínculos com a faculdade e não havia um corpo docente organizado e articulado que pudesse nos servir de referência. Além disso, não dispúnhamos de material bibliográfico nacional e os poucos livros estrangeiros a que tínhamos acesso propunham modelos de reabilitação distantes de nossa realidade e das instituiçóes assistenciais que visitávamos.

Éramos autodidatas, trocávamos "traduçôes livres", buscávamos profissionais com mais experiência, visitávamos instituiçôes de saúde e reabilitação, organizávamos cursos extracurriculares, tentando somar esforços tanto para melhorar nossas condiçôes de aprendizado quanto para desvendar os mistérios daquela profissão que encantava e desafiava. Essas preocupaçóes eram partilhadas com colegas que tinham os mesmos anseios e expectativas e, juntos, criávamos um movimento que buscava novas bases para o ensino de Terapia Ocupacional e para a própria profissão. Não é por acaso que boa parte do atual corpo docente do curso de Terapia Ocupacional da USP tenha se graduado naquela época e participado desse movimento.

Meu início de carreira como terapeuta ocupacional clínica, em hospitais psiquiátricos, ocorreu entre 1979 e 1981. Foi marcado pela militância, pelo desejo de transformar e de mudar a realidade daquelas instituiçóes, o atendimento em Saúde Mental, e o próprio status de minha profissão. Desde então, interessei-me pela articulação entre os campos da Saúde Mental e o da Saúde Coletiva, pois entendia que, para mudar a realidade daqueles hospitais, a construção de uma rede de serviços para cuidados extra-hospitalares era imprescindível. Essa constatação levou-me a participar ativamente de um movimento pela humanização da assistência psiquiátrica e da criação de dispositivos extra-hospitalares que, naquela época, articulava-se em torno do Centro Brasileiro de Estudos de Saúde (CEBES).

Logo percebi que precisava de embasamento teórico, entretanto, faltavam mestres, faltava literatura científica e, além disso, a formação acadêmica que havia recebido na graduação era insuficiente. Foi quando fiz, em 1979, um curso de Especialização em Saúde Mental com capacitação em Saúde Pública, na Faculdade de Saúde Pública da USP. Era uma proposta pioneira visando formar trabalhadores da área de Saúde Mental, em uma perspectiva multidisciplinar, para atuarem na atenção primária. Esse curso e o convívio com colegas de outras áreas de várias regiôes do país possibilitaram-se ampliar a visão sobre saúde, Saúde Mental e políticas de saúde e contextualizar minha prática nesses campos para além da reabilitação que, na época, era restrita à atenção terciária. Participei, também, da organização do Centro de Estudos de Terapia Ocupacional em Saúde Mental (CETO) que, mais tarde, organizou-se como um curso de especialização.

\section{Iniciando a vida}

\section{acadêmica - implantação do curso de Terapia Ocupacional da Universidade Federal de São Carlos}

Em 1981, ingressei como docente da área social na Universidade Federal de São Carlos - UFSCar. Lá tive a oportunidade de trabalhar com um grupo de terapeutas ocupacionais na implantação de um 
novo curso de graduaçáo, de montar os alicerces de uma nova área de atuação e de continuar me capacitando e construindo minha participação na consolidação da profissão.

A Universidade Federal de São Carlos era uma universidade jovem, com ideias inovadoras, onde havia um Centro de Ciências Biológicas e da Saúde com dois departamentos. Os cursos de Fisioterapia, Enfermagem e Terapia Ocupacional, incluindo a área básica, integravam o Departamento de Ciências da Saúde. Sermos os únicos cursos da área da saúde possibilitava um espaço de atuação diferenciado, permitindo a criaçáo de projetos inovadores, de novos campos de atuação e de currículos diferenciados. Tive oportunidade de participar do desmembramento gradativo do Departamento de Ciências da Saúde até a constituição do Departamento de Terapia Ocupacional daquela universidade, constatando a importância da autonomia institucional para que esses cursos pudessem crescer e se consolidar. Mesmo após meu desligamento, em 1991 - ao ingressar na USP -, foi com muito orgulho que acompanhei a evolução dos colegas de departamento: o professor José Rubens Rebellato, do curso de Fisioterapia, tornou-se reitor da UFSCar e a professora Maria Luisa Guillaumon Emmel foi conduzida à chefia do Centro de Ciências Biológicas e da Saúde e, depois, à Pró-Reitoria de Extensão daquela universidade.

Comecei a trabalhar na universidade muito jovem, como docente de uma área também jovem, sem tradição científica ou acadêmica no Brasil, com colegas igualmente jovens e numa universidade jovem. Por isso, meu desenvolvimento profissional, em diversos momentos, mescla-se com o desenvolvimento da Terapia Ocupacional, seja nas instituiçóes onde atuei, seja no próprio país.

No Departamento de Ciências da Saúde da UFSCar encontrei um grupo de colegas produtivos e idealistas. Foram durante os 11 anos passados ali que entendi a importância social da universidade e da capacitação para a pesquisa e os desafios que iria enfrentar para construir uma trajetória científica e acadêmica para a Terapia Ocupacional. Além disso, trabalhar na UFSCar contribuiu para o acúmulo do capital intelectual e da bagagem necessária para avançar na carreira universitária, bem como poder enfrentar os desafios que surgiriam a seguir.

Meu ingresso precoce na universidade impôs-me desafios para os quais eu ainda não estava preparada. Aos poucos, fui encontrando meios, parceiros e a maturidade necessária para superá-los, tanto pelo investimento em minha própria formação e capacitação, quanto pela participaçáo no debate profissional, que ocorria, em âmbito nacional, no interior da Terapia Ocupacional e nos movimentos sociais no campo da saúde: Reforma Psiquiátrica, busca pela cidadania e pela inclusão de deficientes físicos, inclusão da temática da reabilitação na atençáo primária, entre outros.

Com essa motivação e junto com meus colegas da UFSCar desenvolvemos diversas atividades no âmbito da graduação. Buscamos rever o conteúdo das disciplinas, criar campos de atuação inovadores para os estágios e aulas práticas e acrescentar, aos currículos, o campo da Saúde Coletiva e das políticas de saúde. Procuramos, também, ampliar o campo da Terapia Ocupacional para além da área da saúde, dialogando com campos sociais, da educação, do trabalho, da cultura e trazendo essas ideias para a formaçáo dos terapeutas ocupacionais. Participamos de um movimento no estado de São Paulo junto com colegas do curso de Terapia Ocupacional da FMUSP e da Pontifícia Universidade Católica de Campinas (PUC-Campinas) para a revisão do currículo mínimo de graduação junto ao Ministério da Educação, buscando um currículo mais humanista e aumentando a proporção de conteúdos advindos das ciências humanas. Organizamos, com docentes de outros cursos de Terapia Ocupacional do país, e em especial da FMUSP, encontros cujo intuito era somar esforços para criar as bases, para avançar e consolidar o ensino de graduação em Terapia Ocupacional no Brasil. Somos uma geraçáo de precursores tanto das bases curriculares dos cursos de graduação como das bases teóricas e práticas da profissão no país.

A UFSCar tinha ainda outro diferencial, que era o investimento na capacitaçáo de seus professores, estimulando o ingresso em programas de mestrado e doutorado, propiciando afastamentos para a capacitação, participando em parceria com o Conselho Nacional de Desenvolvimento Científico e Tecnológico (CNPq) de programas de fomento a bolsas de estudo para professores (Programa de Incentivo à Capacitação Docente - PICD).

Foi com esse espírito que, ao buscar um curso de mestrado, me deparei, na época, com uma orientação política que não privilegiava a interdisciplinaridade. Os programas de Medicina Preventiva, Saúde Pública e Saúde Mental - campos que me interessavam - ou não eram abertos a profissionais não médicos ou ofereciam pouquíssimas vagas para candidatos com o meu perfil acadêmico. Daí minha opção em cursar o mestrado de Saúde Comunitária na Universidade Federal da Bahia (UFBA), no então Departamento de Medicina Preventiva, hoje Instituto de Saúde Coletiva, reconhecido nacional e internacionalmente como importante centro formador e de pesquisa 
nessa área e que era, já naquela época, pioneiro na interdisciplinaridade em seu programa de pós-graduação.

Nesta mesma ocasião, conheci o professor José Augusto Guilhon de Albuquerque, então docente do curso de Ciências Sociais da Universidade de São Paulo, conceituado teórico da temática das instituições asilares, tema que eu desejava estudar. Optei por não cursar o mestrado em Ciências Sociais, devido a meu interesse pela Saúde Coletiva, e, em concordância com o professor Guilhon, que aceitou ser meu orientador, fui fazer meu mestrado na UFBA.

Durante os dois anos em que morei em Salvador pude obter uma sólida formação na área de Saúde Coletiva, o que me levou a compreender as políticas de Saúde Mental, dentro de um contexto mais amplo, e a me interessar pelo campo da Saúde do Trabalhador. Ter sido aluna de mestres como Naomar Almeida Filho e Jairnilson Silva Paim é até hoje marco importante na minha formaçáo.

Após esse período, retornei a São Paulo para desenvolver minha dissertação de mestrado sob a orientação do professor Guilhon de Albuquerque. Ao buscar refletir sobre o funcionamento e a organização dos hospitais psiquiátricos públicos no estado de Sáo Paulo encontrei no Juqueri as condições propícias para a realização da dissertação "A loucura do Outro: o Juqueri no discurso de seus protagonistas", concluída em 1988. O Juqueri, além de ser considerado pela opinião pública o protótipo de um hospital psiquiátrico tradicional, era palco de uma série de mudanças e discussóes que julgamos ser interessante acompanhar, registrar e avaliar.

$\mathrm{Na}$ continuidade de meus estudos, mantive meu interesse integrando o campo da Saúde Coletiva e o da Saúde Mental. O Departamento de Psiquiatria e Psicologia Médica da Universidade Estadual de Campinas (Unicamp) iniciou o programa de Pós-Graduação em Saúde Mental e que contava, entre seus orientadores, com o professor Everardo Duarte Nunes, uma importante referência nacional e internacional no âmbito das Ciências Sociais e da Saúde, atraindo-me para lá. Candidatei-me ao programa tendo o privilégio de ser selecionada. Era uma excelente oportunidade para ampliar e dar continuidade à temática que havia iniciado no mestrado: instituiçôes psiquiátricas e sociedade. Surge daí minha tese de doutorado: Loucura e espaço urbano, Franco da Rocha e o Asilo do Juqueri, defendida em 1995 e publicada como livro anos depois. Se o convívio com o professor Guilhon ensinou-me o rigor necessário para o trabalho de pesquisadora e deu-me as bases teóricas para entender a complexa relação entre instituiçôes de saúde e sociedade, o convívio com o professor Everardo trouxe-me maturidade e a possibilidade de um aprofundamento teórico ímpar, assim como permitiu que integrasse minhas reflexóes aos debates sobre Saúde Coletiva, que havia iniciado na Universidade Federal da Bahia. Até hoje o professor Everardo é um importante interlocutor com quem tenho a oportunidade de conviver.

\section{Primeiros anos na \\ Universidade de São Paulo}

Com o nascimento do meu primeiro filho, Gabriel, em 1989, e a decisão de morar em São Paulo-SP, eu tive que rever minha permanência na UFSCar. No início de 1991, recebi um convite para integrar, como assessora de Saúde Mental do distrito do Butantã, a equipe da Secretaria Municipal de Saúde da Prefeitura de Sáo Paulo, o que me afastou das atividades universitárias e do programa de doutorado por quase um ano. Durante este período, apesar da oportunidade de contribuir na construção de serviços e de políticas de Saúde Mental e de Saúde Pública, refleti sobre minha vocação acadêmica e minha responsabilidade na constituição científica e acadêmica da Terapia Ocupacional.

Foi com esse espírito que, no final de 1991, prestei o concurso para docente no curso de Terapia Ocupacional da FMUSP, ingressando nesta instituição no início de 1992, entusiasmada em somar meus esforços aos dos colegas, vários dos quais já conhecia no contexto da graduação e com quem já partilhava discussóes acadêmicas de âmbito estadual e nacional.

Encontrei um grupo de trabalho fértil e inovador, uma instituição com sólida tradição em pesquisa e o desafio de mudar o patamar do curso de Terapia Ocupacional tanto junto da FMUSP quanto da universidade como um todo. Ministrei diversas disciplinas na graduação, inicialmente na área de fundamentos de Terapia Ocupacional e reabilitação profissional. Com a reestruturação curricular em 2002, pude formalizar o conteúdo da Saúde do Trabalhador como disciplina teórico-prática no novo currículo de graduação. Participei de comissóes administrativas, fui coordenadora do curso de graduação em 1995 e em 2001, acompanhei ativamente a constituição do Departamento de Fisioterapia, Fonoaudiologia e Terapia Ocupacional, e no final de 1999 me integrei à comissão que, após anos sucessivos de trabalho, viabilizou a criação do Programa de Pós-Graduação em Ciências da Reabilitação, em 2005. 
A minha geração de terapeutas ocupacionais e meu grupo de trabalho na FMUSP, em particular, participaram da elaboração e da consolidação em âmbito ministerial e de secretarias estaduais e municipais de diversas políticas públicas que visavam assegurar a cidadania de pessoas portadoras de desvantagem, a inclusão de diversas populaçóes em risco, do encampar a temática da reabilitação na atenção primária, da implementação da Reforma Psiquiátrica e da construção de redes de atenção extra-hospitalares. Certamente, temos o mérito de termos não somente militado e feito avançar essas políticas no país quanto de ter ampliado o campo da atuação da Terapia Ocupacional e demonstrado o potencial da nossa contribuição nesses campos. Simultaneamente construímos teorias, práticas e tecnologias para fazermos frente a essas demandas que ajudávamos a fomentar. Todas essas atividades demandaram de nosso corpo docente e da nossa geração tempo e investimento muito grandes, o que concorreu com outras formas de produção científica estrito senso mais consideradas no meio acadêmico. Partilhávamos a sensação de que era necessária, antes, a construção dos caminhos para, depois, podermos percorrê-los; de que era necessário constituir e sermos constituídos a um só tempo e de que a Terapia Ocupacional estava sendo construída a partir de esforços pioneiros de seus profissionais e que as demandas para consolidar esse processo eram múltiplas, complexas e simultâneas.

\section{Construindo parâmetros para a Terapia Ocupacional}

Meu envolvimento com as questôes da Terapia Ocupacional na graduação, em âmbito nacional, resultou em um convite para integrar a Comissão de Especialistas de Ensino em Terapia Ocupacional e Fisioterapia, ligada à Secretaria de Ensino Superior do Ministério de Educação, em 1995. Com o desmembramento dessa comissão em duas - a de Fisioterapia e a de Terapia Ocupacional -, em 1998, permaneci no cargo como coordenadora da Comissão de Terapia Ocupacional até 2000. Como membro e coordenadora dessas comissóes, participei junto com colegas de outras instituições do país, entre outras atividades, da elaboraçáo de diretrizes curriculares e de padróes mínimos para os cursos de Terapia Ocupacional em âmbito nacional, da definição de indicadores nacionais para a abertura de novos cursos etc. Pude, ainda, integrar comissóes avaliadoras de abertura e reconhecimento de diversos cursos em todo o país.

\section{Definindo uma linha de pesquisa}

Em relação à pesquisa, ao finalizar o doutorado, no início de 1995, ano em que nasceu minha filha Ana, comecei a buscar outras possibilidades de articulação entre os campos da Saúde Mental, Saúde Coletiva e Terapia Ocupacional. Foi com essas idéias que comecei a me aproximar da área de Saúde Mental e Trabalho, que vislumbrava como oportunidade de síntese de meus interesses e como um importante campo de atuação e investigação da Terapia Ocupacional a ser desenvolvido e que não vinha recebendo a devida atenção por parte dos pesquisadores na época. $\mathrm{Na}$ busca de autores e teorias que relacionassem esses campos, o encontro com a obra do professor Christophe Dejours e com a Psicodinâmica do Trabalho foi uma oportuna descoberta. O professor Dejours é uma importante referência nacional e internacional na área de Trabalho e Saúde Mental. Tive a oportunidade de conhecê-lo durante um seminário na USP, em 1997, e desse breve convívio e troca de ideias veio o estímulo para realizar meu primeiro pós-doutorado no Laboratoire de Psychologie du Travail et de l'Action - LPTA, do Conservatoire National des Arts et Metiers - CNAM, em Paris, no período de setembro de 1999 a abril de 2000, sob sua orientação.

Encontrei, na equipe do LPTA, os parceiros e o ambiente intelectual necessários para os caminhos que desejava percorrer. Estabeleci, então, um vínculo científico sólido. Desde 2002, sou pesquisadora associada desse laboratório e venho frequentando suas reuniōes, seminários e colóquios com regularidade, na França. No Brasil, junto com outros pesquisadores - entre os quais destaco o professor Laerte Sznelwar, do Departamento de Engenharia de Produção da Escola Politécnica da USP, e o professor Seiji Uchida, da Fundação Getulio Vargas, temos divulgado as bases teóricas e metodológicas da Psicodinâmica do Trabalho, por meio da promoção de eventos com pesquisadores nacionais e estrangeiros, do diálogo com outras disciplinas como a Ergonomia, Sociologia e Psicologia do Trabalho e a promoçáo e publicaçôes de livros, de seminários, nacionais e internacionais, do desenvolvimento de pesquisas conjuntas, de orientaçóes etc.

Foi ao longo de minha participação nas atividades no LPTA que conheci a equipe de Psychodynamique $d u$ Travail do Quebec (PDTQ), Canadá, com a qual passei a estabelecer diversos intercâmbios que permitiram o ensino e as atividades de pesquisa no Quebec e no Brasil. Fazem parte desta equipe, 
entre outros, os professores Micheline Saint-Jean e Pierre-Yves Therriaut, do curso de Terapia Ocupacional da Universidade de Montreal, e os professores Louis Trudel, professor titular do curso de Terapia Ocupacional da Universidade de Laval, Quebec, além dos professores Michel Vezina e Louise St-Arnauld, também da Universidade de Laval. Esse contato permitiu-me estabelecer parcerias também com os cursos de Terapia Ocupacional dessas duas universidades, assim como aproximar a reflexão teórica da Terapia Ocupacional com o campo da Saúde e Trabalho, da Saúde Mental e Trabalho, Saúde do Trabalhador e, mais especificamente, com a Psicodinâmica do Trabalho.

Fruto dessa parceria, do meu interesse em aprofundar a articulação da Terapia Ocupacional com a Psicodinâmica do Trabalho e conhecer melhor o modelo canadense de Terapia Ocupacional nessa área, em 2007 realizei um segundo pós-doutorado na Universidade de Montreal, Canadá. Contei como anfitrióes, de um lado, o curso de Terapia Ocupacional da Universidade de Montreal, por meio da professora Micheline Saint-Jean, e de outro a École des Hautes Etudes Commercial (HEC Montreal), através da professora Estelle Morin, diretora do Centro de Pesquisa e Intervençáo para o Trabalho, Eficácia Organizacional e Saúde (Centre de Recherche et d'Intervention pour le Travail, l'Efficacité Organisationnelle et la Santé - CRITEOS).

Da parceria com a Universidade de Montréal e com a Universidade de Laval têm resultado cursos, seminários, intercâmbios e pesquisas tanto no Brasil como no Canadá. No Canadá, pude ministrar, por duas vezes, a disciplina Atuação de Terapia Ocupacional no Brasil para os alunos de graduação do curso de Terapia Ocupacional da Universidade de Montreal, em 2004 e em 2007. Esse curso, de 30 horas, que contou também com a participaçáo de professores e de profissionais terapeutas ocupacionais canadenses, focava bases $\mathrm{da}$ Terapia Ocupacional brasileira nos diferentes campos de atuação. Essa experiência foi uma oportunidade ímpar para divulgar nossas ideias, teorias e práticas, mas também de constatar o interesse e importância do conhecimento que vimos construindo. Pude participar de reunióes de graduação e pós-graduação, conhecer novos projetos pedagógicos, conhecer serviços de reabilitação profissional, participar de projetos de pesquisa e colocar minhas ideias de pesquisa e minha produção numa conexão internacional.

Como contrapartida, tenho participado da organização de seminários no Brasil com a presença de professores canadenses, organizado seminários e reunióes científicas, entre outras. Destaco o Seminário Internacional de Saúde, Trabalho e Terapia Ocupacional, na FMUSP, em junho de 2004, que contou com a participação dos professores Micheline Saint-Jean e Louis Trudel, além de diversos professores de Terapia Ocupacional, do Brasil, interessados no tema, e o Seminário Internacional de Políticas Públicas e Processo de Trabalho em Saúde Mental, em 2007, o VI Colóquio Internacional de Psicodinâmica e Psicopatologia do Trabalho e o I Congresso da Associaçáo Internacional de Especialistas em Psicodinâmica do Trabalho, em 2010.

No início de 2008, recebi um convite do professor Dejours para integrar, como membro fundadora, a Association Internationale des Spécialistes en Psychodynamique du Travail-AISPDT (Associação Internacional de Especialistas em Psicodinâmica do Trabalho). Essa associação pretende reunir pesquisadores de diversas partes do mundo para o desenvolvimento do campo, desenvolvimento de projetos de pesquisa multicêntricos, intercâmbio de alunos de pós-graduação e pesquisadores, e conta, ainda, entre seus membros fundadores, com pesquisadores da França, Canadá, México e Suíça.

Sou responsável, desde 2000, pelo Laboratório de Investigação e Intervenção em Saúde e Trabalho - LIIST, do Departamento de Fisioterapia, Fonoaudiologia e Terapia Ocupacional da FMUSP, que contou com a participaçáo de terapeutas ocupacionais amigas e colaboradoras, de alunos bolsistas de iniciação científica, mestrandos, doutorandos e bolsistas de capacitação técnica. Todas essas pessoas, aliadas aos colegas que já passaram pelo laboratório, meus recentes orientandos e orientados têm sido parceiros e interlocutores imprescindíveis na construção e consolidação da linha de pesquisa "Saúde, Trabalho e Terapia Ocupacional".

O LIIST desenvolve atividades de ensino, pesquisa e extensão, através de disciplinas teóricas na graduação e no Programa de Pós-Graduaçáo em Ciências da Reabilitação, de estágios de formação profissional, de programa de residência multiprofissional, de orientação de trabalhos de conclusão de curso e de bolsistas de iniciação científica, de alunos de mestrado e doutorado e do desenvolvimento de diversos projetos de pesquisa. Sua linha de pesquisa propóe abordagens inovadoras na Terapia Ocupacional como, por exemplo, pesquisa e intervençóes em situaçóes de trabalho causadoras de sofrimento psíquico, pesquisas em clínica do trabalho com destaque para a Psicodinâmica do Trabalho, desenvolvimento de novas abordagens voltadas para a reabilitaçáo profissional e retorno de trabalhadores afastados que privilegiam o enfoque holístico, a identificação 
e superaçáo de aspectos dificultadores, tanto do retorno quanto da permanência no trabalho. É com interesse que tenho acompanhado a repercussão das nossas ideias tanto em ex-bolsistas e ex-alunos que ingressam com sucesso no mercado de trabalho, inclusive na docência, quanto em pesquisadores, profissionais e serviços de Atenção à Saúde do Trabalhador.

\subsection{Construindo a titularidade e assumindo novos desafios}

Em 2004, com o mesmo pioneirismo que vem acompanhando minha trajetória acadêmica, fui a primeira terapeuta ocupacional no país e prestar o concurso de livre-docência na FMUSP tendo sido aprovada. Nessa ocasião, apresentei a tese: "Saúde Mental e Trabalho: repensando a ação em Terapia Ocupacional”, estudo síntese sobre como venho articulando os vários campos de pesquisa que venho desenvolvendo com a Terapia Ocupacional. $\mathrm{Na}$ carreira da USP, esse exame é um pré-requisito para o concurso de professor titular e, embora não seja competitivo, é talvez uma das etapas mais difíceis da carreira nessa universidade.

Dessa forma, quando em 2008 o curso de Terapia Ocupacional da USP foi contemplado com uma vaga de professor titular, eu era a candidata nata a esse posto.

Na USP, e em particular na FMUSP, o professor titular é, antes de tudo, perante a instituição, um líder acadêmico responsável pelo desenvolvimento do seu campo de atuaçáo. Cabe ao professor titular assumir chefias, comissōes, dar maior visibilidade e possibilidades para a Terapia Ocupacional na Faculdade de Medicina e na USP como um todo. É atribuição, também do professor titular, coordenar as atividades vinculadas ao Complexo Hospitalar do Hospital das Clínicas - maior complexo hospitalar da América Latina. Dessa forma, tenho enfrentado o desafio de articular açóes do curso de Terapia Ocupacional, com açôes desenvolvidas nesse complexo por mais de 150 terapeutas ocupacionais, em serviços consolidados há muito tempo. Esse novo desafio tem me exigido um amadurecimento ímpar e por vezes muito solitário. Tenho revivido a sensação que tinha no começo da minha carreira de que era necessário, antes, a construção dos caminhos para, depois, podermos percorrê-los, de que era necessário constituir e ser constituída a um só tempo.

\section{Novos tempos para a Terapia Ocupacional}

Muitos desafios ainda se colocam e se, de um lado, pudemos consolidar e expandir a graduação, participar e influenciar a abertura de diversos cursos públicos de Terapia Ocupacional no país, ampliar o campo da Terapia Ocupacional para a atençáo primária, para o campo social e do trabalho, há muito ainda a ser feito. O dinamismo das mudanças sociais, epidemiológicas e nas políticas de saúde no país traz a necessidade de que estejamos sintonizados com essas mudanças para mantermos nosso trabalho sincronizado com as novas demandas surgidas com a contemporaneidade.

Talvez o maior desafio que devemos enfrentar é a formação de novos pesquisadores que possam prosseguir, avançar e continuar a desenvolver nosso campo de forma sustentável e cumulativa. Para isso, a consolidação e ampliação da nossa participação em programas de pós-graduaçáo, o aumento do volume de financiamento de projetos de pesquisa na nossa área e, sobretudo, o aumento da quantidade de publicaçóes, tanto em revistas indexadas e de maior impacto quanto na sustentação e promoção dos nossos periódicos, se fazem presentes.

A Terapia Ocupacional no país vem passando por mudanças, das quais destaco a abertura de uma quantidade expressiva de novos cursos de graduação em escolas públicas estaduais e federais. Isso vem permitindo um aumento importante no número de professores voltados para a pesquisa e para a produção de conhecimento na área.

Para assegurarmos nossa possibilidade de contribuir nesse processo, a ampliação da nossa participação na pós-graduação é premente e diversas iniciativas têm sido construídas visando otimizar a capacidade produtiva do grupo no que se refere às exigências atuais dos cursos de pós-graduação, tais como fomento e consolidaçáo de linhas e grupos de pesquisa, aglutinaçáo de professores em torno de projetos e publicaçóes comuns, aumento do aporte e do número de projetos de pesquisa enviados a agências financiadoras. No âmbito das publicaçôes em revistas de maior impacto também estamos adotando estratégias coletivas e colaborativas que permitam simultaneamente o aumento quantitativo e qualitativo dessas publicações. Acredito que é na confluência das singularidades e contribuiçóes específicas de cada um dos grupos de pesquisa potencializadas em produçóes coletivas que encontraremos a sinergia necessária para o nosso crescimento e consolidaçáo na pós-graduação. 


\section{Bibliografia}

GONÇALVES, R. M. A. et al. Ergonomic work analysis to reorganize parking inspection agents'work productivity, health and safety in São Paulo, Brazil. Work, Reading, v. 36, p. 345-353, 2010.

LANCMAN, S. Réflexions sur la constitution du champ de L'Ergothérapie au Brésil. Journal d'Ergothérapie, Paris, v. 20, n. 2, p. 85-89, 1998.

LANCMAN, S. Loucura e Espaço Urbano, Franco da Rocha e o asilo do Juqueri. Rio de Janeiro; Belo Horizonte: Te-Corá Editora, 1999.

LANCMAN, S. Saúde, Trabalho e Terapia Ocupacional. In: LANCMAN, S. Saude do Trabalhador e Terapia Ocupacional. São Paulo: Ed. Roca, 2004. p. 71-83.

LANCMAN, S. Psicodinâmica do trabalho: uma abordagem em Saúde Mental e Trabalho e Terapia Ocupacional. In: CAVALCANTI, A.; GALVÃO, C. (Orgs.). Terapia Ocupacional: Fundamentação \& Práticas. Rio de Janeiro: Guanabara Koogan, 2007. p. 271-277.

LANCMAN, S. Politicas Públicas e processo de trabalho em saúde mental. São Paulo: Paralelo 15, 2008.

LANCMAN, S. et al. Violência no trabalho e saúde mental em um serviço de pronto atendimento hospitalar. In: ASSUNÇÃO, A. A.; BRITO, J. Trabalhar na saúde, experiências cotidianas e desafios para a gestão do trabalho e do emprego. Rio de Janeiro: FIOCRUZ, 2011. p. 111-130.

LANCMAN, S.; EMMEL, G. La Recherche en Ergotherapie: développement de la formation des enseignants au Brésil. Canadian Journal of Occupational Therapy, Toronto, v. 70, n. 2, p. 97-100, 2003.
LANCMAN, S. et al. A invisibilidade da violência no trabalho e suas relaçóes com a saúde mental dos trabalhadores. Revista de Saúde Pública, São Paulo, v. 43, p. 682-688, 2008.

LANCMAN, S.; JARDIM, T. A. Aspectos subjetivos do morar e trabalhar na mesma comunidade: a realidade vivenciada pelo agente comunitário de saúde. Interface: Comunicação, Saúde, Educação, Botucatu, v. 13, n. 28, p. 123-145, 2009. http://dx.doi.org/10.1590/ S1414-32832009000100011

LANCMAN, S.; SZNELWAR, L. Christophe Dejours da psicopatologia a Psicodinâmica do Trabalho. ed. rev e ampl. Brasília: Paralelo15; Rio de Janeiro: FIOCRUZ, 2008.

LANCMAN, S. et al. Un Agent de Santé Communautaire: Un Travail aù l'on s'expose. Travailler, Revue Internacionale de Psychopathologie et de Psychodynamique du Travail, Paris, n. 17, p. 97-124, 2007.

SILVA, M. T.; LANCMAN, S.; ALONSO, C. M. C. Consequências da intangibilidade na gestão dos novos serviços de saúde mental. Revista de Saúde Pública, São Paulo, v. 43, p. 36-42, 2009. Suplemento 1.

SZNELWAR, L. I.; UCHIDA, S.; LANCMAN, S. Subjectivity at work in question. Tempo Social, São Paulo, v. 23, p. 11-30, 2011.

UCHIDA, S. et al. O trabalhar em serviços de saúde mental: entre o sofrimento e a cooperação. Laboreal, Porto, v. 7, p. 28-41, 2011.

UCHIDA, S.; SZNELWAR, L.; LANCMAN, S. Aspects épistemologiques et méthodologiques de la psychodynamique du travail. Travailler, Revue Internacionale de Psychopathologie et de Psychodynamique du Travail, Paris, n. 25, p. 29-44, 2011. 